\title{
Effect of Oral Gabapentin and Pregabalin in the Management of Neuropathic Pain in Palliative Care Patients: An Institution- based Comparative Study
}

\author{
Nipun Lamba ${ }^{1}$, Ruchika Makkar ${ }^{2}$, Namita Gupta $^{3}$, Sudha Sarna ${ }^{4}$, Seema Khandelwal ${ }^{5}$
}

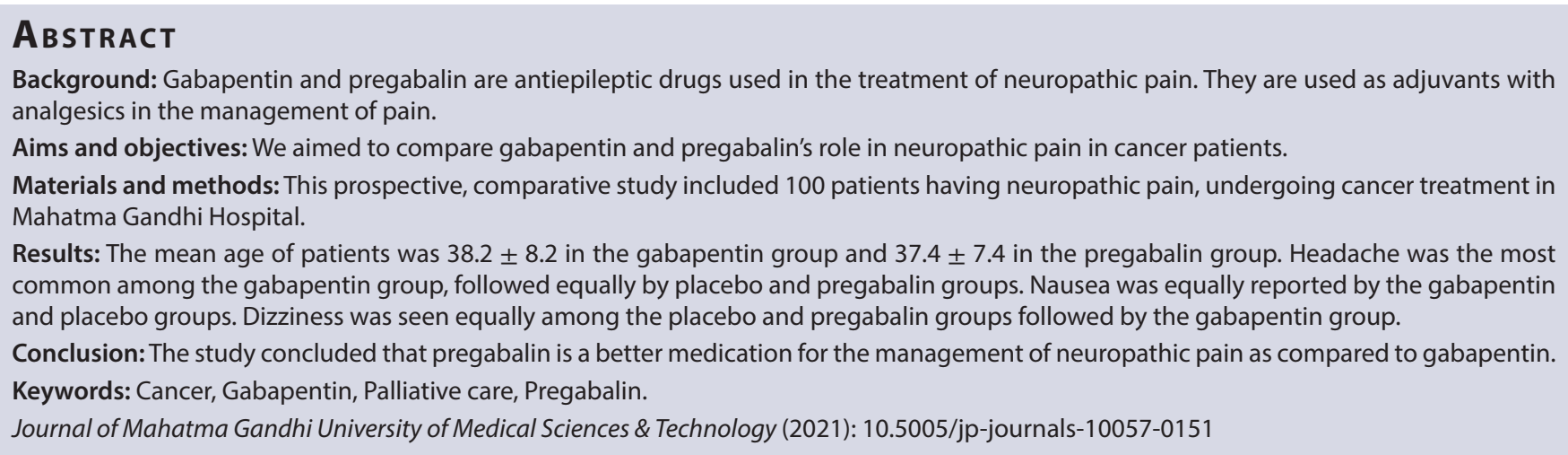

\section{INTRODUCTION}

Neuropathic medications are increasingly being used in the management of neuropathic pain along with adjuvants in the management of pain. Pain in cancer is the most fearsome symptom along with the disease itself. Proper management of pain is necessary. Multimodal analgesia and newer medications had reduced the incidence of neuropathic as well as postsurgical pain. ${ }^{1}$ It was observed that when we are unable to give proper analgesic pain worsens and the patient might need admission again causing an increase in financial burden. ${ }^{2}$ Because of neuropathic pain quality of life is hampered. ${ }^{3,4}$ Sleep disturbances, anxiety, and various other problems may coexist. ${ }^{4}$ It was observed that giving pain medicines before painful stimulus gives better results than giving after. $^{5}$

\section{Materials and Methods}

We had undergone a present study in the Department of Pain and Palliative Medicine, Mahatma Gandhi Hospital, Jaipur, India. The study design was a prospective randomized observational study of 100 patients suffering from cancer having painful neuropathy. In a prospective randomized study, 50 patients were allocated randomly into two equal groups.

Due permission was taken from the institutional ethics committee and after obtaining written informed consent from patients. Patients in group $\mathrm{G}$ were given gabapentin $300 \mathrm{mg}$ at bedtime whereas group $P$ received pregabalin $75 \mathrm{mg}$. The pain was recorded using the VAS scale. Follow-up was done over a period of a month (Tables 1 to 4 ).

We have formed two groups for comparison.

- Group I: 50 cases, were given pregabalin, beginning with 75 mg.

- Group II: 50 cases, were given gabapentin, beginning with $300 \mathrm{mg}$.

\footnotetext{
${ }^{1-5}$ Department of Pain and Palliative Medicine, Mahatma Gandhi Medical College and Hospital, Jaipur, Rajasthan, India

Corresponding Author: Nipun Lamba, Department of Pain and Palliative Medicine, Mahatma Gandhi Medical College and Hospital, Jaipur, Rajasthan, India, Phone: +91 9529725485, e-mail: dr. nipunlamba@yahoo.com

How to cite this article: Lamba N, Makkar R, Gupta N, et al. Effect of Oral Gabapentin and Pregabalin in the Management of Neuropathic Pain in Palliative Care Patients: An Institution-based Comparative Study. J Mahatma Gandhi Univ Med Sci Tech 2021;6(2):46-47.

Source of support: Nil

Conflict of interest: None
}

\section{Inclusion Criteria}

- Patients undergoing cancer treatment having neuropathic pain.

Table 1: Patients demographics

\begin{tabular}{llll}
\hline & $\begin{array}{l}\text { Pregabalin } \\
(n=50)\end{array}$ & $\begin{array}{l}\text { Gabapentin } \\
(n=50)\end{array}$ & pvalue \\
\hline Age (years) & $37.4 \pm 7.4$ & $38.2 \pm 8.2$ & $>0.05$ \\
Sex male/ & $22 / 28$ & $18 / 32$ & $>0.05$ \\
female & & & \\
Weight $(\mathrm{kg})$ & $72.4 \pm 5$ & $71 \pm 6$ & $>0.05$ \\
\hline
\end{tabular}

The mean age in the pregabalin group was $37 \pm 7.4$ and gabapentin was $38.2 \pm 8.2$, having a $p$ value $>0.05$. These groups were comparable. Weight in the pregabalin group was $72.4 \pm 5$ and gabapentin was $71 \pm 6$. $p$ value $>0.05$

\footnotetext{
(c) The Author(s). 2021 Open Access This article is distributed under the terms of the Creative Commons Attribution 4.0 International License (https:// creativecommons.org/licenses/by-nc/4.0/), which permits unrestricted use, distribution, and non-commercial reproduction in any medium, provided you give appropriate credit to the original author(s) and the source, provide a link to the Creative Commons license, and indicate if changes were made. The Creative Commons Public Domain Dedication waiver (http://creativecommons.org/publicdomain/zero/1.0/) applies to the data made available in this article, unless otherwise stated.
} 
Table 2: Incidence of burning sensation

\begin{tabular}{llllll}
\hline & \multicolumn{3}{c}{ Study population with a burning sensation } \\
\cline { 2 - 3 } \cline { 5 - 5 } $\begin{array}{l}\text { Duration in } \\
\text { weeks }\end{array}$ & \multicolumn{3}{c}{ Pregabalin $(n=50)$} & & \multicolumn{2}{c}{ Gabapentin $(n=50)$} \\
\cline { 2 - 3 } \cline { 5 - 6 } No. of cases & $\%$ & & No. of cases & $\%$ \\
\hline Baseline & 50 & 100.0 & & 50 & 100.0 \\
1 Week & 46 & 92.0 & & 47 & 94.0 \\
2 Weeks & 45 & 90.0 & & 48 & 96.0 \\
3 Weeks & 44 & 88.0 & & 47 & 94 \\
4 Weeks & 40 & 80.0 & & 42 & 84.0 \\
\hline
\end{tabular}

A burning sensation is reduced at 1,2, 3, and 4 weeks $92,90,88$, and $80 \%$ and in gabapentin in $94,96,94$, and $84 \%$

Table 3: Incidence of spontaneous pain

\begin{tabular}{lllll}
\hline & \multicolumn{3}{c}{ Study population with spontaneous pain } \\
\cline { 2 - 5 } Duration in & \multicolumn{3}{c}{ Pregabalin $(n=50)$} & \multicolumn{2}{c}{ Gabapentin $(n=50)$} \\
\cline { 2 - 5 } weeks & No. of cases & $\%$ & No. of cases & $\%$ \\
\hline Baseline & 40 & 80.0 & 39 & 78.0 \\
1 Week & 38 & 76.0 & 37 & 74.0 \\
2 Weeks & 36 & 72.0 & 36 & 72.0 \\
3 Weeks & 34 & 68.0 & 36 & 72.0 \\
4 Weeks & 33 & 66.0 & 34 & 68.0 \\
\hline
\end{tabular}

Spontaneous pain at 1, 2, 3, and 4 weeks showed more improvement with pregabalin than gabapentin

Table 4: VAS score

\begin{tabular}{lcc}
\hline VAS score & Pregabalin & Gabapentin \\
\hline Baseline & $8.64 \pm 2.80$ & $8.62 \pm 3.57$ \\
At 4 weeks & $3.96 \pm 5.54$ & $4.62 \pm 4.89$ \\
Mean improvement & $4.68 \pm 4.97$ & $4.00 \pm 4.54$ \\
\hline
\end{tabular}

VAS score improvement in the pregabalin group was $8.64 \pm 2.80$ and in the gabapentin group, $8.62 \pm 3.57$ at 4 weeks was $3.96 \pm 5.54$ and in gabapentin $4.62 \pm 4.87$. Mean improvement $4.68 \pm 4.97$ and the gabapentin group was $4.00 \pm 4.54$

\section{Exclusion Criteria}

- Patient refusal.

- Patients having organ dysfunction.

- Patients with altered sensorium or disturbed orientation.

\section{Adverse Effects}

\begin{tabular}{lccl}
\hline & $\begin{array}{l}\text { Pregabalin } \\
(n=50)\end{array}$ & $\begin{array}{l}\text { Gabapentin } \\
(n=50)\end{array}$ & $p$ value \\
\hline Nausea & $10(20 \%)$ & $9(18 \%)$ & $>0.05$ \\
Vomiting & $8(16 \%)$ & $10(20 \%)$ & $>0.05$ \\
Dizziness & $7(15 \%)$ & $7(17.5 \%)$ & $>0.05$ \\
Drowsiness & $4(8 \%)$ & $4(8 \%)$ & $>0.05$ \\
Headache & $4(8 \%)$ & $5(10 \%)$ & $>0.05$ \\
Visual disturbances & $1(2 \%)$ & $2(4 \%)$ & $>0.05$ \\
Urine retention & $0(0 \%)$ & $0(0 \%)$ & \\
Respiratory depression & $0(0 \%)$ & $0(0 \%)$ & \\
\hline
\end{tabular}

There was an incidence of nausea, vomiting, dizziness, drowsiness, headache, and visual disturbances. There was no incidence of urinary retention and respiratory depression.

\section{Discussion}

Cancer-related pain is the most common cause of morbidity and mortality. Neuropathic pain causes distress and financial losses. We have compared gabapentin and pregabalin for the management of neuropathic pain in cancer patients. Respective medications were given for 30 days and their effects on pain, burning sensation were seen. Also, their adverse effects were noted, and numbness was evaluated. The pain was evaluated by the use of the VAS scale and the patients' response. Yilmaz et al. found no statistically significant difference between gabapentin and pregabalin in neuropathic pain. ${ }^{6}$ Richter et al. ${ }^{7}$ reported that pregabalin $300 \mathrm{mg} /$ day provides $>50 \%$ reduction in pain from baseline in about $40 \%$ of total patients. Rosenstock et al. ${ }^{8}$ described a $67 \%$ reduction in neuropathic pain in patients treated with pregabalin.

Lesser et al. ${ }^{9}$ also reported that gabapentin and pregabalin groups provide better pain relief than which was also in accordance with the findings of the current study. ${ }^{10}$

Gabapentin and pregabalin are used for the management of neuropathic pain in cancer patients, both are effective in the management of pain

\section{Conclusion}

According to the results of our study, both gabapentin and pregabalin are suitable adjuvants along with analgesics for the management of neuropathic pain in cancer patients.

\section{References}

1. Vadivelu N, Mitra S, Narayan D. Recent advances in postoperative pain management. Yale J Biol Med 2010;83(1):11-25.

2. Sinatra R. Causes and consequences of inadequate management of acute pain. Pain Med 2010;11(12):1859-1871. DOI: 10.1111/j.15264637.2010.00983.x.

3. Rodriguez MJ, Diaz S, Vera-Llonch M, et al. Cost-effectiveness analysis of pregabalin versus gabapentin in the management of neuropathic pain due to diabetic polyneuropathy or postherpetic neuralgia. Curr Med Res Opin 2007;23(10):2585-2596. DOI: 10.1185/030079907X233151.

4. Navarro A, Saldaña MT, Pérez C, et al. A cost-consequences analysis of the effect of pregabalin in the treatment of peripheral neuropathic pain in routine medical practice in primary care settings. BMC Neurol 2011;11(1):1. DOI: 10.1186/1471-2377-11-7.

5. Saraswat V, Arora V. Preemptive gabapentin vs pregabalin for acute postoperative pain after surgery under spinal anaesthesia. Ind J Anaes 2008;52:829-834

6. Yilmaz B, Yasar E, Koroglu OO, et al. Gabapentin vs pregabalin for the treatment of neuropathic pain in patients with spinal cord injury: a crossover study. Turk J Phys Med Rehab 2014;61(1):1-5. DOI: 10.5152/ tftrd.2015.79069.

7. Richter RW, Portenoy R, Sharma U, et al. Relief of painful diabetic peripheral neuropathy with pregabalin: a randomized, placebo-controlled trial. J Pain 2005;6(4):253-260. DOI: 10.1016/j. jpain.2004.12.007.

8. Rosenstock J, Tuchman M, LaMoreaux L, et al. Pregabalin for the treatment of painful diabetic peripheral neuropathy: a double-blind, placebo controlled trial. Pain 2004;110(3):628-638. DOI: 10.1016/j. pain.2004.05.001.

9. Lesser H, Sharma U, LaMoreaux L, et al. Pregabalin relieves symptoms of painful diabetic neuropathy A randomized controlled trial. Neurology 2004;63(11):2104-2110. DOI: 10.1212/01.wnl.0000145767.36287.a1.

10. Mishra R, Tripathi M, Chandola HC. Comparative clinical study of gabapentin and pregabalin for postoperative analgesia in laparoscopic cholecystectomy. Anesth Essays Res 2016;10(2):201-206. DOI: 10.4103/0259-1162.176409. 